\title{
Chimeric antigen receptor T cell targeting EGFRvIII for metastatic lung cancer therapy
}

\author{
Zhao Zhang ${ }^{1,2, *}$, Jun Jiang ${ }^{3, *}$, Xiaodong $\mathrm{Wu}^{1,2}$, Mengyao Zhang ${ }^{4}$, Dan Luo ${ }^{1,2}$, Renyu Zhang ${ }^{1,2}$, Shiyou Li (凶) $)^{3}$, \\ Youwen He $(\bowtie)^{5}$, Huijie Bian $(\bowtie)^{1,2}$, Zhinan Chen $(\bowtie)^{1,2}$ \\ ${ }^{1}$ National Translational Science Center for Molecular Medicine, Xi'an 710032, China; ${ }^{2}$ Department of Cell Biology, Fourth Military Medical \\ University, Xi'an 710032, China; ${ }^{3}$ Beijing Institute of Genomics, Chinese Academy of Science, Beijing 100101, China; ${ }^{4}$ Beijing Institute of \\ Biotechnology, Academy of Military Medical Sciences, Beijing 100142, China; ${ }^{5}$ Department of Immunology, Duke University Medical \\ Center, Durham, NC 27710, USA
}

(C) The Author(s) 2019. This article is published with open access at link.springer.com and journal.hep.com.cn

\begin{abstract}
Lung cancer is the most common incident cancer and the leading cause of cancer death. In recent years, the development of tumor immunotherapy especially chimeric antigen receptor $T$ (CAR-T) cell has shown a promising future. Epidermal growth factor receptor variant III (EGFRvIII) is a tumor-specific mutation expressed in various types of tumors and has been detected in non-small cell lung cancer with a mutation rate of 10\%. Thus, EGFRvIII is a potential antigen for targeted lung cancer therapy. In this study, CAR vectors were constructed and transfected into virus-packaging cells. Then, activated $T$ cells were infected with retrovirus harvested from stable virus-producing single clone cell lines. CAR expression on the surfaces of the $T$ cells was detected by flow cytometry and Western blot. The function of CAR-T targeting EGFRvIII was then evaluated. The EGFRvIII-CAR vector was successfully constructed and confirmed by DNA sequencing. A stable virus-producing cell line was produced from a single clone by limited dilution. The culture conditions for the cell line, including cell density, temperature, and culture medium were optimized. After infection with retrovirus, CAR was expressed on more than $90 \%$ of the $T$ cells. The proliferation of CAR-T cells were induced by cytokine and specific antigen in vitro. More importantly, EGFRvIII-CART specifically and efficiently recognized and killed A549-EGFRvIII cells with an effector/target ratio of 10:1 by expressing and releasing cytokines, including perforin, granzyme B, IFN- $\gamma$, and TNF- $\alpha$. The in vivo study indicated that the metastasis of A549-EGFRvIII cells in mice were inhibited by EGFRvIII-CART cells, and the survival of the mice was significantly prolonged with no serious side effects. EGFRvIII-CART showed significantly efficient antitumor activity against lung cancer cells expressing EGFRvIII in vivo and in vitro. Therefore, CAR-T targeting EGFRvIII is a potential therapeutic strategy in preventing recurrence and metastasis of lung cancer after surgery.
\end{abstract}

Keywords chimeric antigen receptor $\mathrm{T}$ cells; epidermal growth factor receptor; lung cancer; immunotherapy; tumor immunology

\section{Introduction}

The incidence of cancer in China has increased rapidly

Received July 24, 2018; accepted December 20, 2018

Correspondence: Zhinan Chen, znchen@fmmu.edu.cn;

Huijie Bian, hjbian@fmmu.edu.cn;

Youwen He, youwenhe65@gmail.com;

Shiyou Li, lishiyou@big.ac.cn

*These authors contributed equally to this study. since the 21st century [1,2]. In 2015, approximately 4292000 of cancer cases was reported in China, with mortality reaching up to 2814000 and five-year-overall survival rate of $36.9 \%$. Lung cancer is the most common incident cancer and the leading cause of cancer death [3]. Despite the continuous progress in traditional treatments, including surgery, chemotherapy, and radiotherapy, the prognosis of lung cancer, especially for advanced stage, is far from satisfactory [4]. The metastasis in advanced stage remains a tricky problem in medical practice [5].

The immune system plays an important role in inhibiting 
tumor progression. Unfortunately, the function of the immune system is impaired during tumor progression [6]. Adoptive cell therapy (ACT), which was initiated by Dr. Rosenberg in 1985 [7], provided a new antitumor strategy focusing on reestablishing or enhancing immune response in tumor patients through the use of reinfusion immune effector cells. The most successful attempt in recent years was the chimeric antigen receptor $\mathrm{T}$ (CAR-T) cells, which have the specificity of antibodies and the cytotoxicity of $\mathrm{T}$ lymphocytes. These CAR-T cells are engineered to express synthetic receptors redirecting $\mathrm{T}$ cells to recognize and kill tumor cells precisely and rapidly, without the limitation of major histocompatibility complex [8]. CAR-T achieved remarkable success in the treatment of leukemia. Patients with acute lymphoblastic leukemia achieved complete remission through CD19-CART therapy $[9,10]$. Despite the success in hematological malignancies, CAR-T treatment for solid tumors is still under investigation and constrained by limited optimal targets [11].

Epidermal growth factor receptor variant III (EGFRvIII), one of the most common mutations of epidermal growth factor receptor (EGFR), is a tumor specific mutation expressed in various types of tumor cells including neuroblastoma [12,13], breast cancer [14], and ovarian cancer [15]. EGFRvIII has been detected in nonsmall cell lung cancer with a mutation rate ranging from $16 \%$ to $39 \%[16,17]$. Moreover, EGFRvIII mutation rate was about $11.1 \%$ in Chinese lung cancer patients [18]. Thus, EGFRvIII is a potential antigen for targeted-therapy in lung cancer.

In this study, we aimed to investigate the antitumor potential of CAR-T cells in lung cancer, especially in the late stage. To this end, the expression vector of the thirdgeneration CAR specific for EGFRvIII was constructed. For further clinical application, stable virus-producing cell clone was selected and CAR-T cells were generated by infection with retrovirus. Then, in vitro and in vivo effects of CAR-T cells in lung cancer therapy were evaluated.

\section{Materials and methods}

\section{Ethics statement}

The design and protocols of this study were approved by the Institutional Ethic Review Board of Fourth Military Medical University.

\section{Cells and animals}

The human lung cancer cell line A549 and the retrovirus producing cell lines Phoenix Eco and PT67 were purchased from American Type Culture Collection (ATCC, Manassas, VA, USA). A549 cells overexpressing EGFRvIII (named A549-EGFRvIII) were established by infection with a retrovirus encoding EGFRvIII. Peripheral blood mononuclear cells (PBMCs) were collected from healthy donors. The A549, Phoenix Eco and PT67 cells were cultured in DMEM medium (Invitrogen, Carlsbad, California, USA) with $10 \%$ fetal calf serum for serial subcultivation. PBMCs were cultured in AIM-V medium (Invitrogen, Carlsbad, California, USA) with 5\% human $\mathrm{AB}$ serum and 300U/mL IL-2 (Sigma, Burlington, MA, USA).

\section{Establishment of the stable retrovirus producing cell line and retrovirus production}

EGFRvIII single chain antibody, CD8 $\alpha$ hinge, CD28, 4$1 \mathrm{BB}$, and $\mathrm{CD} 3 \zeta$ (named EGFRvIII-CAR) and CD8 $\alpha$ hinge, $\mathrm{CD} 28,4-1 \mathrm{BB}$ and $\mathrm{CD} 3 \zeta$ (named MOCK-CAR) were subcloned into pMSCV plasmid (Addgene 20737) and transfected into the virus-packaging cell line. Briefly, Phoenix Eco cells were seeded into $10 \mathrm{~cm}^{2}$ disk, and transfected with plasmids by Lipofectamine 2000 (Invitrogen, Carlsbad, California, USA) at the following ratio: $3 \mu \mathrm{g}$ of DNA per $12 \mu \mathrm{L}$ of lipofectamine according to the manufacturer's instruction. After 24 h, PG13 cells were infected with the retroviruses harvested from the Phoenix Eco packaging cell line in 24-well plate. Single clone cell line, PT67, was established by limited dilution according to a previously described method [19]. The titers of the retrovirus produced by each clone cell line were quantified by real-time PCR.

\section{Isolation of PBMCs and generation of CAR-T cells}

PBMCs were isolated from the peripheral blood of healthy donors. Briefly, $50 \mathrm{~mL}$ of peripheral blood were collected and treated with anticoagulants. The PBMCs were harvested by density gradient centrifugation and cultured in AIM-V containing 5\% human serum and $300 \mathrm{U} / \mathrm{mL}$ IL2. The PBMCs were either cryopreserved or infected by retrovirus. Before retrovirus infection, the PBMCs were activated with $50 \mathrm{ng} / \mathrm{mL}$ OKT-3. The efficiency of the activation was evaluated by flow cytometry. Non-tissuetreated 24-well plates were coated with $100 \mu \mathrm{g} / \mathrm{mL}$ RetroNectin (Takara, Nojihigashi 7-4-38, Kusatsu, Shiga, Japan). The supernatant of the stable virus-producing cell line was collected and filtered. The $5 \times 10^{5}$ activated PBMCs and $1 \mathrm{~mL}$ of virus supernatant were added into the 24-well plate and centrifuged according to the instruction of manufacturer of RetroNectin.

\section{Cell proliferation}

Antigen- and cytokine-dependent cell proliferation was performed in vitro. A549-EGFRvIII cells were cocultured with EGFRvIII-CART, MOCK-CART, and PBMCs at an effector/target ratio of 1:10. Cell number was counted 
every other day after culture. In the cytokine-dependent cell proliferation study, CAR-T cells or PBMCs were cultured in an AIM-V medium supplemented with $3000 \mathrm{U} / \mathrm{mL}$ IL-2 and without the target cells.

\section{Intracellular staining and flow cytometry}

Cell surface fluorescent antibodies against CD45, CD3, $\mathrm{CD} 4$, and CD8 were purchased from BD (USA), and intracellular staining antibodies targeting perforin, granzyme B, IFN- $\gamma$ and TNF- $\alpha$ were purchased from Biolegend (San Diego, CA, USA). Cell intracellular staining was performed according to the instruction of the manufacturer of the intracellular staining kit (BD, San Jose, CA, USA). Single chain antibody against EGFRvIII expressed on the $\mathrm{T}$ cell surface was detected by biotin-protein L (GeneScript, Piscataway, NJ, USA) and Streptavidin-PerCp (BD, San Jose, CA, USA). Matched isotype control antibodies were used in the analysis. Flow cytometry data was analyzed by FlowJo software 7.0 version.

\section{Lactate dehydrogenase release assay and real-time cell analysis system}

The cytolytic activities of the CAR-T cells or PBMCs were measured by lactate dehydrogenase $(\mathrm{LDH})$ release assay. Effective and target cells were cocultured in a 96-well plate at different E:T ratio, and the supernatants were harvested at different times. LDH level was measured with a cytotoxicity detection kit (Promega, Madison, WI, USA). Real-time cell analysis (RTCA) system DP (ACEA Biosciences, San Diego, CA, USA) was used for the plotting of the cytolytic curve of the effect cells.

\section{Enzyme-linked immunosorbent assay}

The amount of cytokine released by the effect cells was measured through enzyme-linked immunosorbent assay (ELISA). Briefly, $1 \times 10^{5}$ CAR-T cells or PBMCs were cocultured with $1 \times 10^{4}$ A549 or A549-EGFRvIII cells respectively for $8 \mathrm{~h}$ at $37{ }^{\circ} \mathrm{C}$. The supernatants were harvested, and the levels of TNF- $\alpha$, IFN- $\gamma$, IL-2, and IL-4 were measured by ELISA according to the manufacturer's instruction (BioLegend, San Diego, CA, USA).

\section{Lung metastasis model}

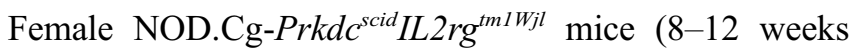
old) were purchased from Vitalstar Biotechnology (Beijing, China) and fed in sterile condition. Thirty-two tumor-bearing mice were randomly assigned to four groups: (1) mice that received A549 cells were treated with EGFRvIII-CART, (2) mice that received A549EGFRvIII cells were treated with PBS, (3) mice that received A549-EGFRvIII cells were treated with MOCK-
CART, and (4) mice that received A549-EGFRvIII cells were treated with EGFRvIII-CART. The $1 \times 10^{6}$ A549 or A549-EGFRvIII cells were administered through tail vein at day 0 , and $1 \times 10^{7}$ EGFRvIII-CART or MOCK-CART cells were administered through the tail vein at 7,10 , and 13 days after tumor cell injection. The mice were observed for 90 days after tumor cells injection. The PBMCs of the mice were collected once a week after the last injection of the effect cells.

\section{Statistical analysis}

All data were presented as mean \pm SE. Statistical analysis was performed in one-way ANOVA for multiple group comparisons and $P$ values less than 0.05 were considered statistically significant. Statistical analysis was performed in PRISM 7.0 software.

\section{Results}

\section{Generation of third-generation CAR targeting EGFRvIII}

For the evaluation of the therapeutic effect of the CAR-T cells in lung cancer, a vector expressing EGFRvIII-CAR was constructed. Single chain antibody against EGFRvIII was synthesized. The single-chain antibody against EGFRvIII and the fragments of CD8 $\alpha$ hinge, hCD28, h4$1 \mathrm{BB}$, and $\mathrm{CD} 3 \zeta$ were subcloned into a pMSCV plasmid by PCR. The MOCK-CAR lacking scFv was constructed as control. The plasmid was confirmed by enzyme digestion and sequence reaction (Fig. 1). The sequence of marker for selection in the vector was deleted for further clinical therapy use, and a similar plasmid encoding EGFP was used as control for the optimization of the experimental conditions.

\section{Optimization of stable retrovirus-producing cell line}

A stable retrovirus-producing cell line was obtained by transient transfecting the CAR vector into Phoenix Eco cell by using Lipotamine 2000. Supernatant containing retrovirus harvested from Phoenix Eco cells was used to infect PT67 cells (Fig. 2A and 2B). By limited dilution culture, PT67-EGFRvIII clone C70 (RV-E70) and PT67-MOCK clone $\mathrm{C} 291$ were established. The retrovirus titers of RVE70 and C291 quantified by real time PCR were $9 \times 10^{9}$ and $7.64 \times 10^{9}$ copies $/ \mathrm{mL}$, respectively. The infection efficiency of the PBMCs was improved by optimizing the culture conditions of the retrovirus-producing cell line, including the initial cell density, temperature of culture condition, and fructose concentration in the medium. As shown in Fig. $2 \mathrm{C}-2 \mathrm{E}$, the retrovirus titer was significantly increased when the producing cells were cultured at an 


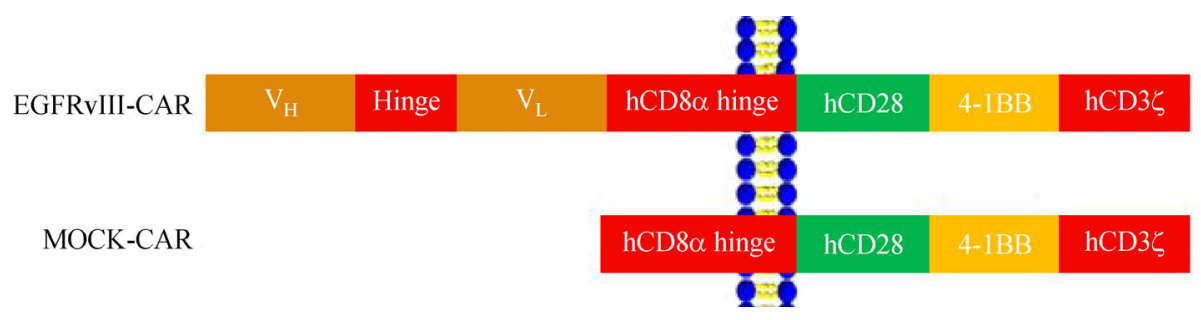

Fig. 1 Expression of chimeric antigen receptor (CAR) of cell membrane. EGFRvIII-CAR was constructed by the extracellular domain of single chain antibody against EGFRvIII, and the intracellular domain consisting of CD28, 4-1BB, and CD3 contains the transmembrane and intracellular domains.

initial density of $4 \times 10^{4}$ cells $/ \mathrm{mL}$ at $37^{\circ} \mathrm{C}$ for $72 \mathrm{~h}$ after the addition of $47 \mathrm{mmol} / \mathrm{L}$ fructose. More importantly, the titers of the clone remained stable after passaging for 10 generations (Fig. 2F).

\section{Generation of CAR-T cells}

CAR-T cells were generated by isolating PBMCs from a healthy donor by density gradient centrifugation. FACS analysis indicated that the PBMCs collected were mainly composed of $\mathrm{T}$ cells and the percentage of the $\mathrm{CD}^{+} \mathrm{CD}^{+}$ $\mathrm{T}$ cells increased after culture (Fig. 3A). To improve the infection efficiency, we used OKT-3, an antibody targeting $\mathrm{CD} 3$, before infection. The successful activation of the $\mathrm{T}$ cells by OKT-3 was confirmed by the increased expression of CD69 and CD25 (Fig. 3B). After infection, CAR expression on $\mathrm{T}$ cell was confirmed by Western blot and FACS analysis. As shown in Fig. 3C, scFv was identified in nearly all the T cells in PBMCs after infection, and this result indicates the efficient generation of CAR-T cells. Western blot analysis showed that $\mathrm{CD} 3 \zeta$ antibody identifies not only the wild type $\mathrm{CD} 3 \zeta(16 \mathrm{kDa})$ molecule but also the molecule fused expression with CAR (43 kDa) (Fig. 3D).

\section{Cytotoxicity of EGFRvIII-CART cells}

The proliferation of EGFRvIII-CART cells, MOCK-CART cells and PBMCs was evaluated. They all showed IL-2 dependent proliferation and no significant differences in proliferation treated with IL-2 (Fig. 4A), which indicated that CAR-T cells retain the same proliferation characteristics as the T cells. However, when cocultured with A549EGFRvIII cells, EGFRvIII-CART cells showed increased proliferation ability compared to MOCK-CART cells and PBMCs (Fig. 4B), indicating that EGFRvIII-CART cells can induce antigen-dependent proliferation.

To further study the cytotoxicity of EGFRvIII-CART cells, we conducted LDH-release assay at E:T ratio of 20:1, 10:1, and 5:1. As shown in Fig. 5A, the three kinds of effect cells showed no significant differences in cytotoxicity on terminal time point (hour 14) at E:T ratio of 20:1, but EGFRvIII-CART can lysis the A549-EGFRvIII cells effectively at early time (hour 4 and 6). As the E:T ratio was reduced to 10:1, EGFRvIII-CART showed significantly greater cytotoxicity in treatment of A549-EGFRvIII cells compared to other groups $(P<0.01)$. At the E:T ratio of $5: 1$, the cytotoxicity of EGFRvIII-CART treated with A549-EGFRvIII cells was slightly reduced. Therefore, the E:T ratio of 10:1 was considered optimization. The same result was also confirmed by RTCA system (Fig. 5B).

The released cytokines after effect cells recognizing tumor cells were then investigated. The intracellular staining showed no significant differences in IFN- $\gamma$, TNF- $\alpha$, granzyme B, and perforin between PBMCs or MOCK-CART cocultured with A549 or A549-EGFRvIII cells (Fig. 6A). However, the EGFRvIII-CART produced high levels of Th1 cytokine IFN- $\gamma$, IL-2 as well as the Th 2 cytokine IL-4 in the supernatants when they cocultured with A549-EGFRvIII cells. EGFRvIII-CART cocultured with A549 cells showed lower cytokines secretion, as well as the MOCK-CART and PBMCs cocultured with tumor cells (Fig. 6B).

\section{Antitumor response of EGFRvIII-CART in vivo}

In vivo antitumor response was evaluated in metastasis model of lung cancer. For the establishment of the advanced lung metastasis model, tumor cells were injected through the tail vein. The mice were observed for 90 days after tumor cell injection. The CAR-T cells were administered 7,10 , and 13 days after the tumor cell injection (Fig. 7A). As shown in Fig. 7B-7D, in the A549EGFRvIII cells treated with PBS, a large number of metastatic lesions formed in the lungs, and mice died because of respiratory failure (median survival 42.5 days). In A549-EGFRvIII treated with MOCK-CART and A549 treated with EGFRvIII-CART, metastatic lesions formed, and the survival rates were improved (median survival 48 and 50 days, respectively). Significantly, less metastatic lesions formed in A549-EGFRvIII treated with EGFRvIIICART group with a survival rate of $62.5 \%$.

We collected CAR-T cells in peripheral blood of the mice once a week to study the in vivo expansion and 
A

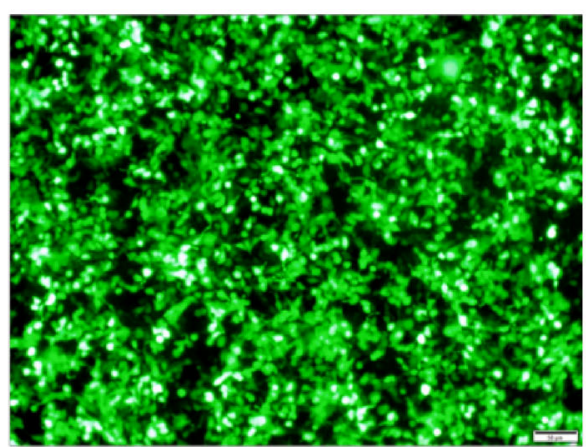

$\mathrm{C}$

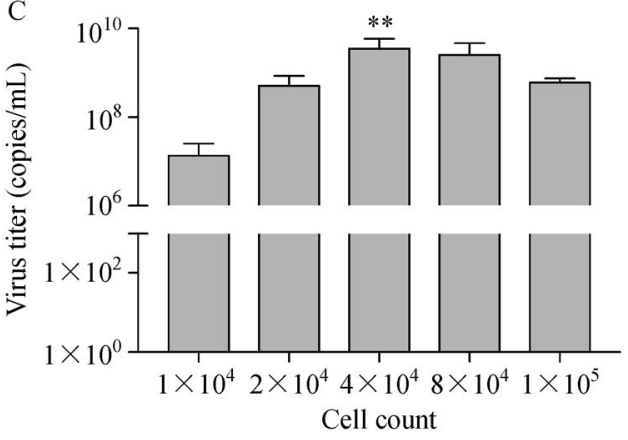

E

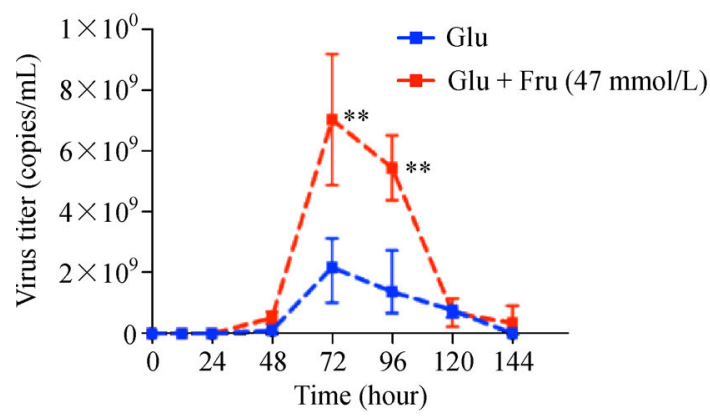

B
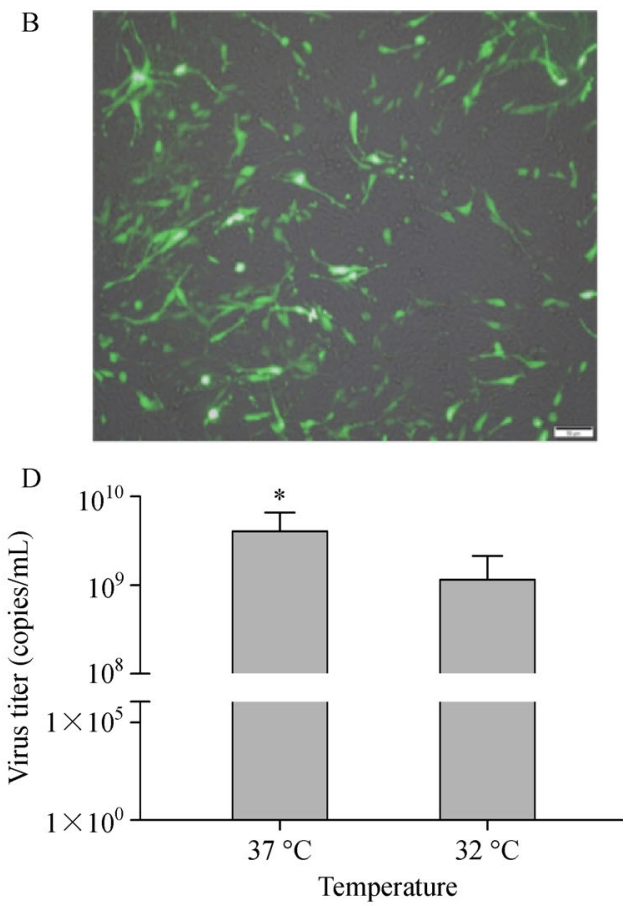

F

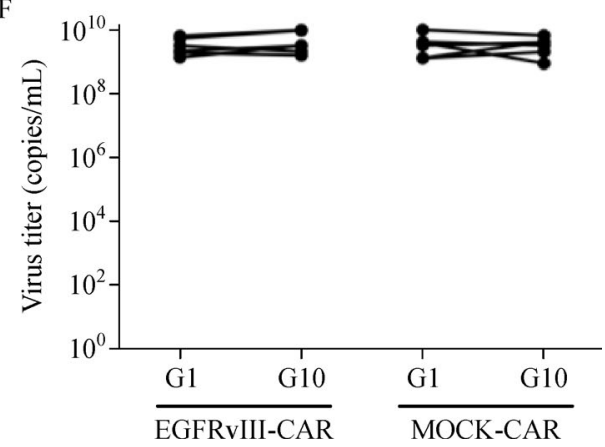

Fig. 2 Establishment of retrovirus-producing cell line and optimization of culture conditions. (A) CAR expression plasmid was transfected into Phoenix Eco cells by lipotamine 2000 (scale bar $=50 \mu \mathrm{m}$ ). (B) PT67 cells were infected by the supernatant of the Phoenix cells (scale bar $=50 \mu \mathrm{m})$. $(\mathrm{C}-\mathrm{E})$ Virus titer of the producing cell line harvested from RV-E70 cultured in different conditions. (F) Virus titers of RV-E70 and MOCK-C291 virus producing cell line after cultured and passaged for 10 generations. ${ }^{*} P<0.05,{ }^{* *} P<0.01$.

survival of CAR-T cells. As shown in Fig. 7E, the human CD3 positive cells significantly decreased over time, and EGFRvIII-CART cells in A549-EGFRvIII mice could remain detectable at 11 th week compared with other groups.

\section{Discussion}

The specificity of the CAR-T cells was determined by the extracellular domain, mainly the single chain antibody of the tumor antigen. Cytotoxicity depended on the intracellular co-stimulator molecules [20]. By using intracellular co-stimulators, three generations of CAR-T were developed. Of the first generation of CAR-Ts, CD3 $\zeta$ was the only molecule in the $\mathrm{T}$ cell [21]. Although effective antitumor immune response could be induced, the lack of effective stimulation signal resulted in the short response time, and poor proliferation in vivo. The antitumor effect of CAR-T cells can be enhanced by adding CD28 and CD137 to the second and third generations of CAR [22,23].

To achieve a satisfactory antitumor effect, we used the third generation CAR-T in the treatment of lung cancer. As the microenvironment of the solid tumor is more complicated than hematologic malignancy, improving the persistence and proliferation of CAR-T cells might maximize their antitumor activity. However, the abrupt release of high-level cytokines caused clinical risk representing by "cytokine storm." [24,25] But in vivo data in our study showed that no mice died of severe side 
A
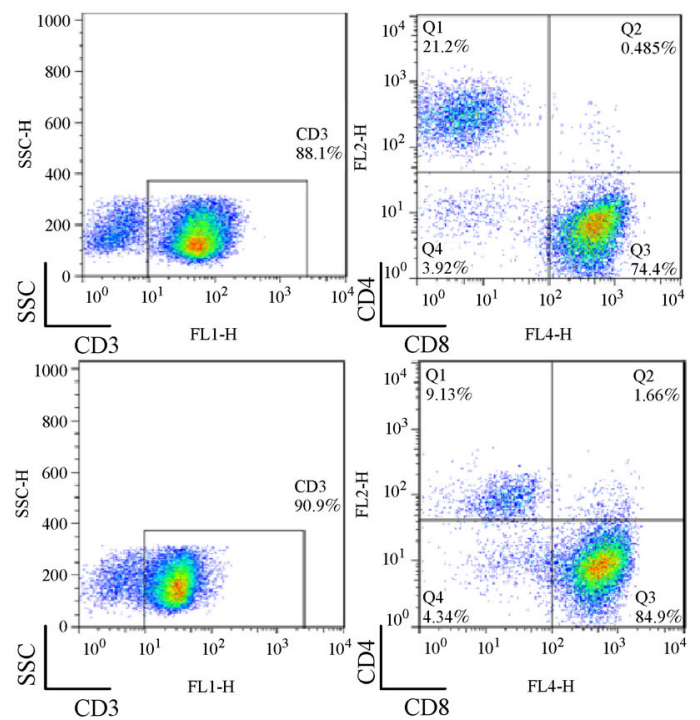

C
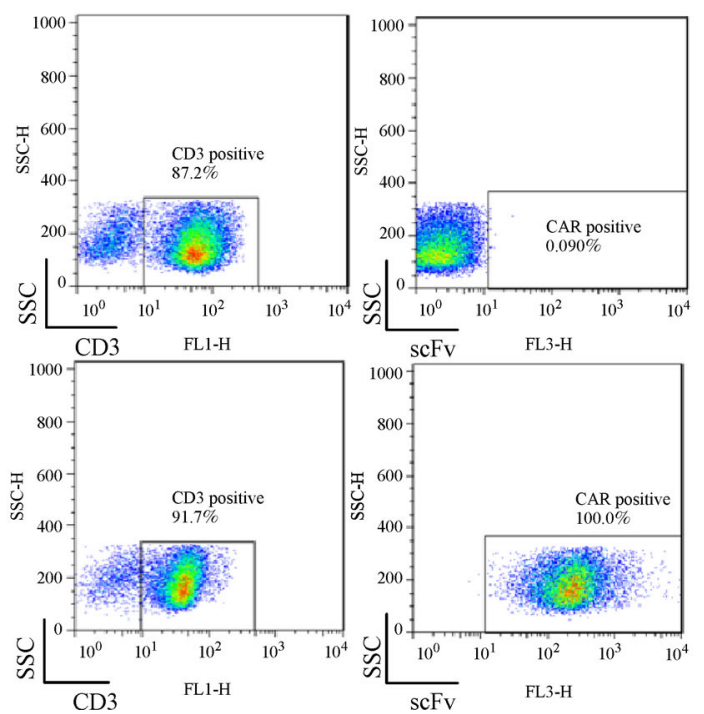

B
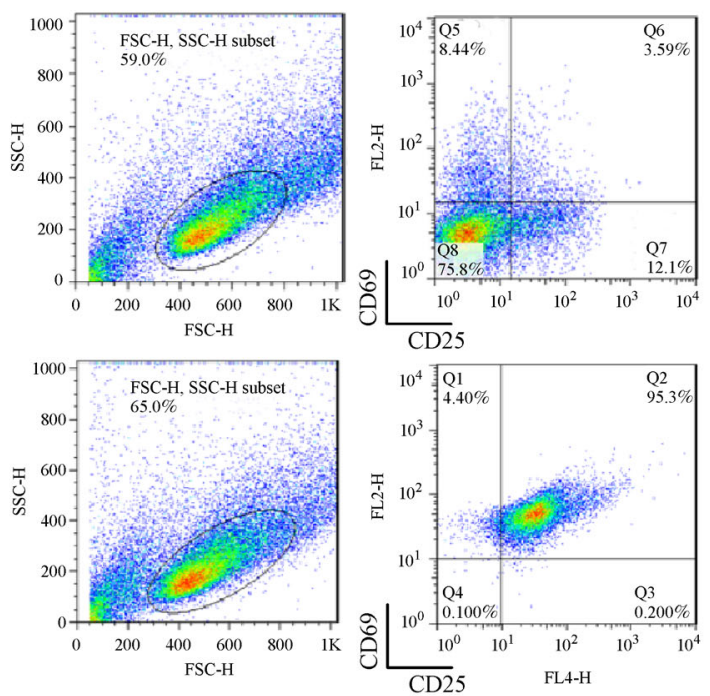

$\mathrm{D}$

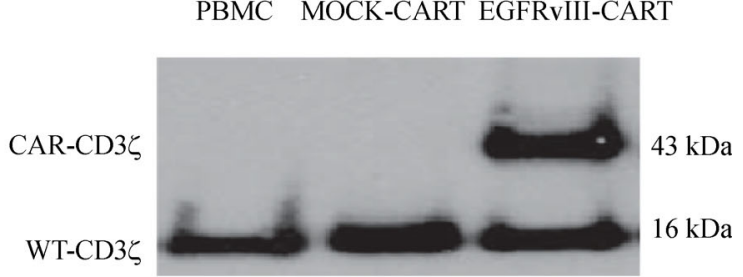

Fig. 3 Isolation and infection of PBMCs. (A) Ratio of $\mathrm{CD}^{+}{ }^{+} \mathrm{CD} 4{ }^{+}$and $\mathrm{CD} 3^{+} \mathrm{CD} 8^{+} \mathrm{T}$ cells in PBMCs before (above) and after (below) cultured in vitro. (B) Expression of CD25 and CD69 before (above) and after (below) T cells were activated by OKT-3 in vitro. (C) Expression of EGFRvIII scFv on uninfected PBMCs (above) and infected PBMCs were detected by FACS analysis. (D) Western blot analysis indicated both wild type $\mathrm{CD} 3 \zeta$ and chimeric antigen receptor $\mathrm{CD} 3 \zeta$ were expressed in $\mathrm{CAR}-\mathrm{T}$ cells.
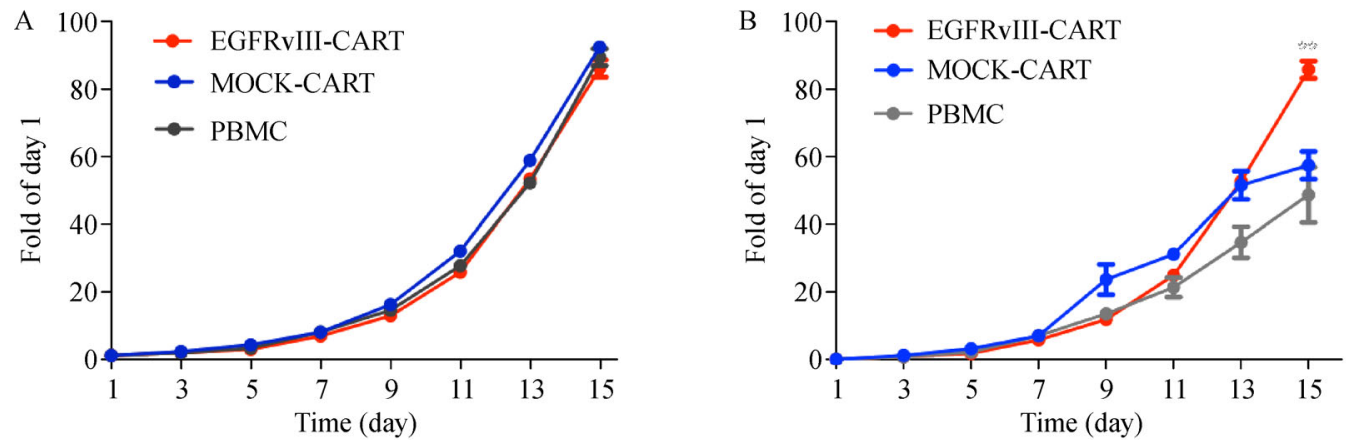

Fig. 4 Proliferation of PBMCs, MOCK-CART and EGFRvIII-CART in vitro. (A) Cytokine dependent cell proliferation. (B) Antigen dependent cell proliferation. $n=8, * * P<0.01$. 


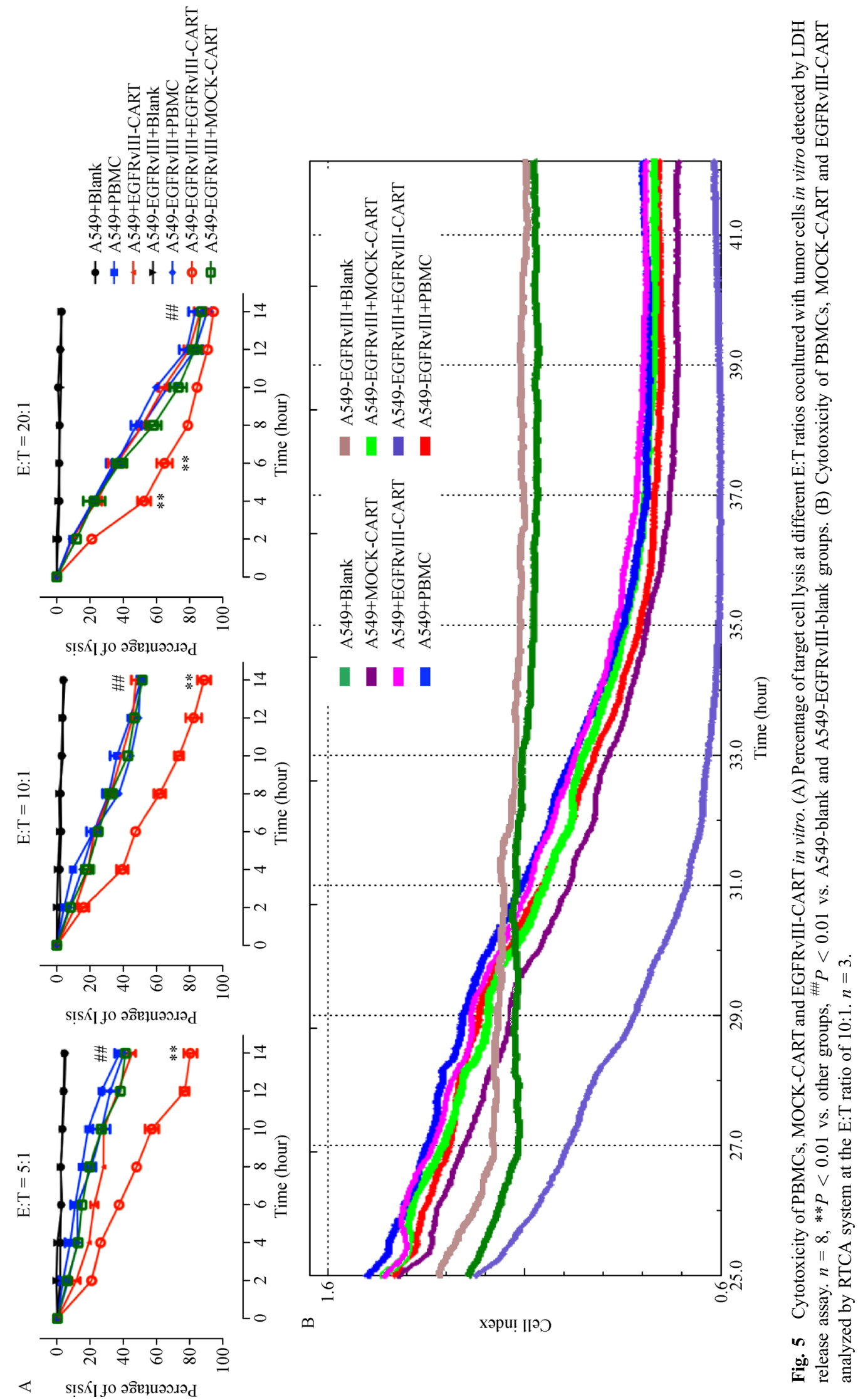


A
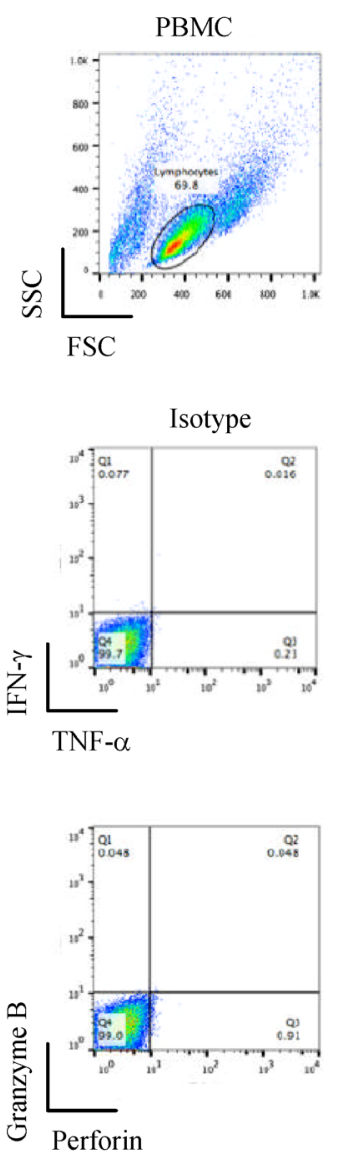

$\mathrm{B}$
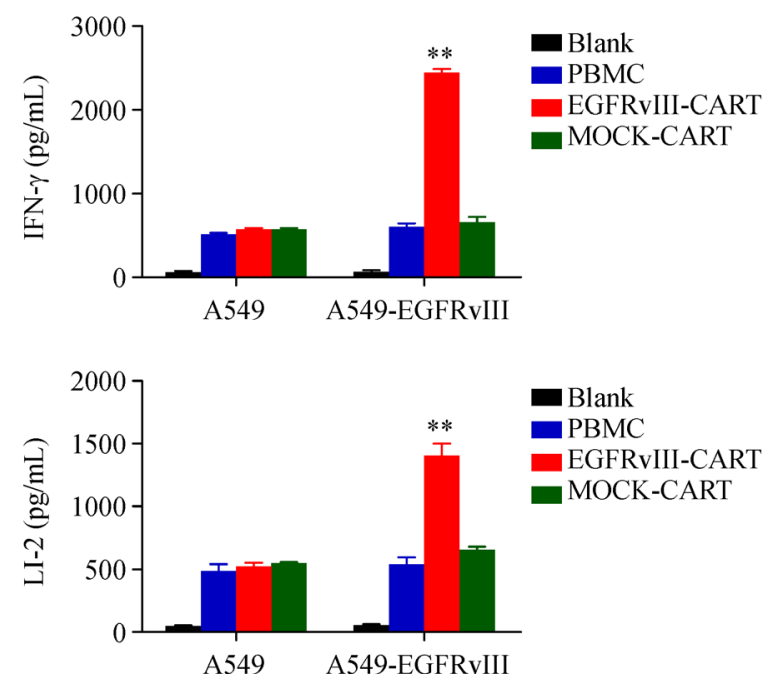

A549

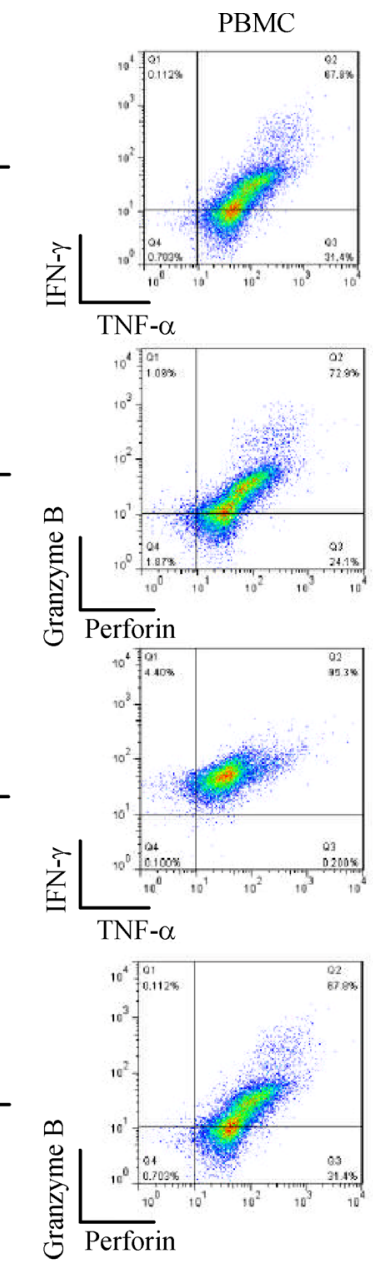

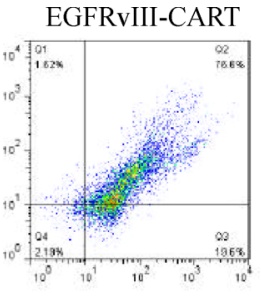
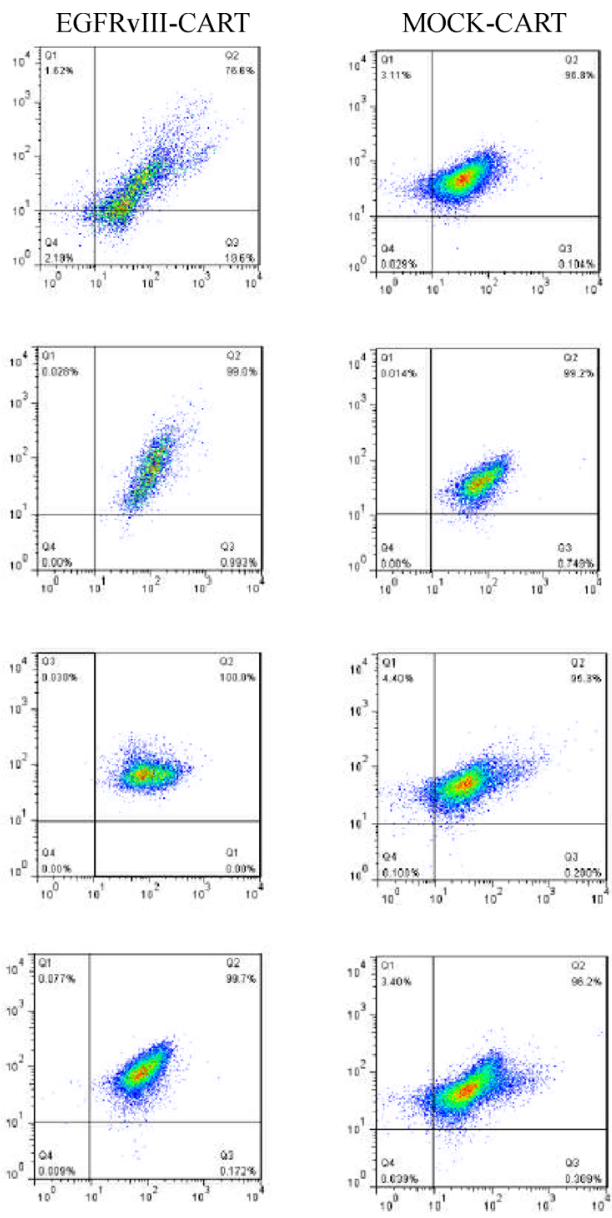

Fig. 6 Expression and release of cytokines of effector cells cocultured with target cells in vitro. (A) Representative results of expression of IFN- $\gamma$, TNF- $\alpha$, granzyme B and perforin in PBMCs, EGFRvIII-CART and MOCK-CART detected by intracellular staining. (B) Cytokines released from effector cells in the supernatant analyzed by ELISA. $n=6,{ }^{* *} P<0.01$. 


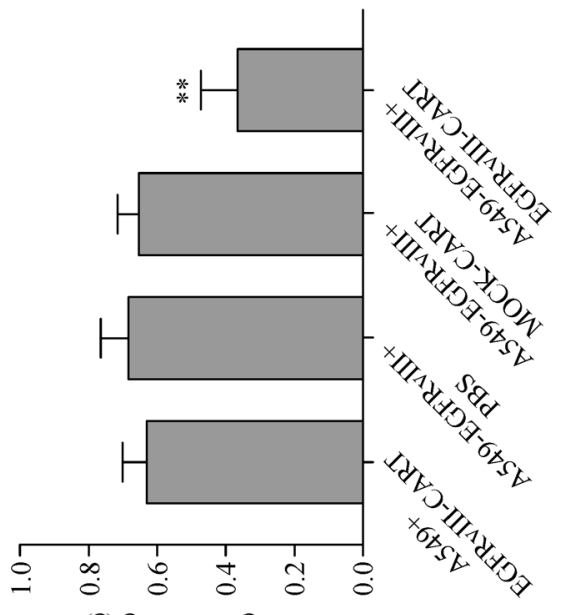

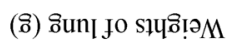

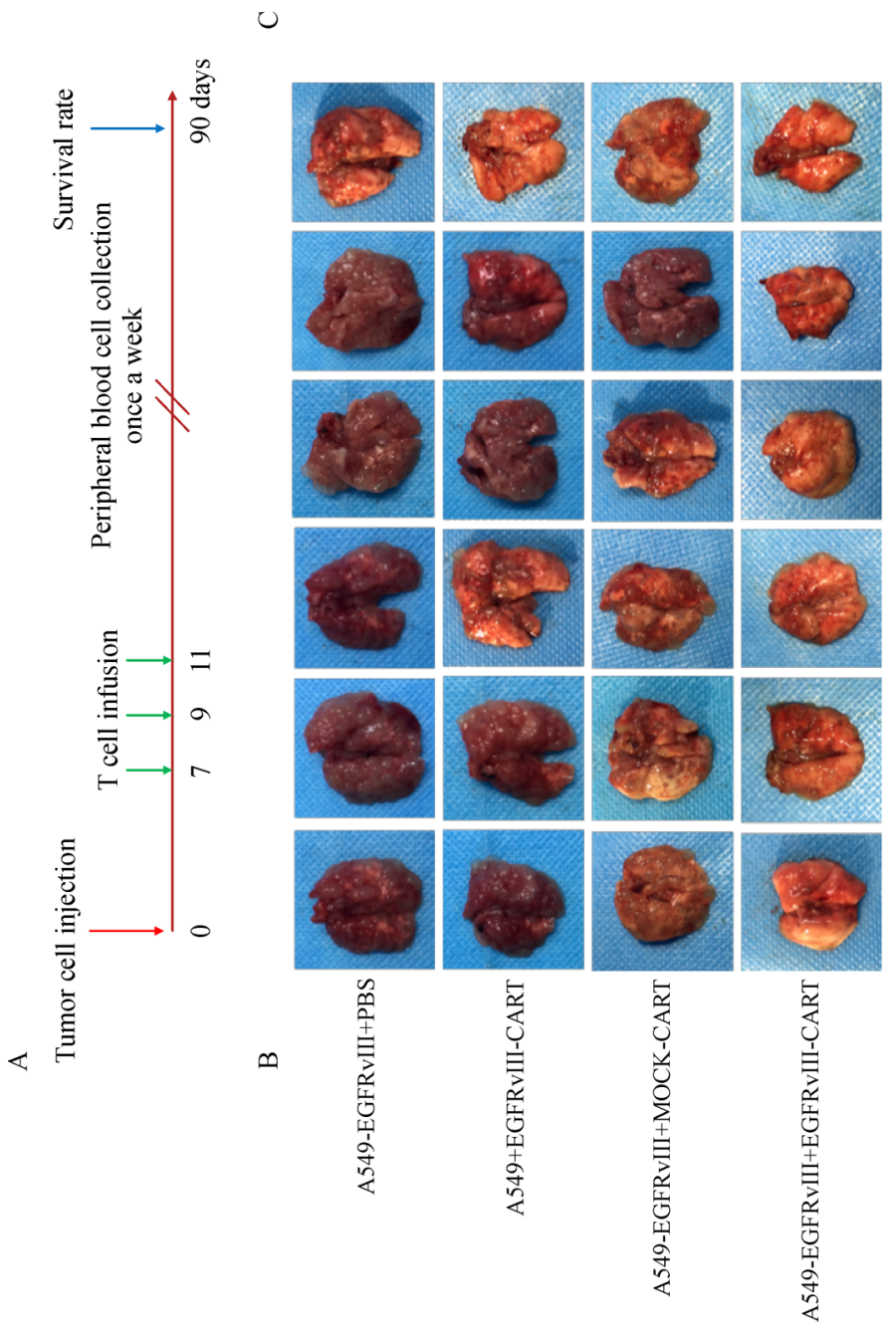

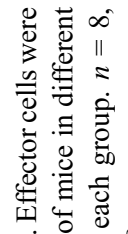

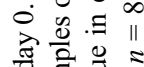

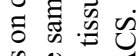

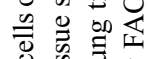

范泀令

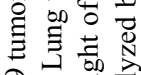

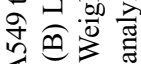

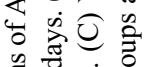

융

远 웡

$\stackrel{0}{\square}$.

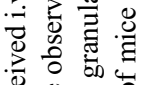

ญ्य

उ

ส

泀灵

해 즌

苨焉

¿

㱐

ठ 아

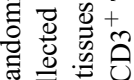

范芯芯

.

ऐ

文运这

ङ.

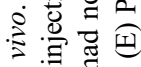

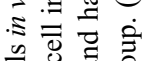

๓

产夆莒

进

$\stackrel{\Xi}{\Xi} \widetilde{\Xi}$

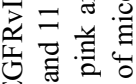

出 $)^{\text {है }}$

记

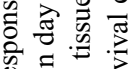

के 웡

क्ष

声元

总苛

- ت

它. 
effects, indicating the safety of third generation CAR-T cells. The appropriate E:T ratio plays an important role in balancing the sufficient antitumor effect and low systematic toxicity. Different E:T ratios were studied in vitro. The results in different groups were compared. In the group with E:T of 5:1, the percentage of lysis of target cells in the terminal time was lower than the percentages of the other groups, and this result may indicate insufficient effector cells. In the group with E:T of 20:1, the targeted tumor cells were lysed in the initial period of experiment. However, no significant difference was observed between the terminal times of the group with E:T of 20:1 and the group with E:T of 10:1, and the abrupt lysis of the mass target cells increased the risk of cytokine storm. Therefore, we selected 10:1 E:T ratio for the in vivo study to achieve the balance between satisfactory antitumor response and number of the effector cells infused into the mice based on the in vitro study.

The antigen targeted in CAR-T therapy should be specific and widely expressed in tumor cells, and thus applying the antigens in solid tumor therapy is difficult. EGFRvIII is a tumor-specific mutation, which results from the in-frame depletion of the 2-7 exons of EGFR. The specific and immunogenic epitope of the extracellular domain is created from the junction of exon 1 and 8 [26]. EGFRvIII was previously studied as a target in glioblastoma, and the results showed that EGFRvIII-CART can control tumor growth in xenogeneic subcutaneous and orthotopic models [27]. More significantly, strategies using CAR-T cells, such as incorporating miR-17-92 mainly to improve T cell survival, showed satisfactory results [28]. In this study, we first constructed the third-generation CAR-T cells targeting EGFRvIII, and evaluated the efficiency in treatment of metastatic lung cancer. As far as the side effects considered in our study are concerned, our data are consistent with those of previous studies [27,28], and no fatal side effects were observed during the in vivo study.

Gene transfection is a major technical problem in CAR$\mathrm{T}$ cell generation. Strategies used in practice can be classified into transient transfection represented by electrotransfection and lipofection transfection, and stable transfection mediated by virus. In our study, we employed retroviruses to achieve the gene modification of lymphocytes. The gene carried by the virus can integrate into the randomly replicated genomes of $\mathrm{T}$ cells during their proliferation. CAR is stably expressed on surfaces of $\mathrm{T}$ cells and prolongs CAR-T persistence in vivo and improves antitumor effect. To prevent the replication of retroviruses in patients, we established a stable virusproducing cell line. The helper plasmids of the retroviruses were integrated into the packaging of the cell genome. The retroviruses used in $\mathrm{T}$ cell infection cannot replicate in the $\mathrm{T}$ cells and meet the standard for clinical use.

The proliferation and persistence of CAR-T cells in vivo had a considerable effect on antitumor therapy. The results in our study indicated that CAR-T cells showed cytokinedependent proliferation and better antigen-dependent proliferation than PBMCs. Cytokine-dependent proliferation enabled the CAR-T cells to expand to the sufficient number before reinfusion to the patient in vitro after infection. Thus, CAR-T cells reinfused into the body proliferated after being triggered by the antigen expressed on the tumor cells. The in vivo study showed that the CAR$\mathrm{T}$ cells remained detectable 11 weeks after reinfusion, indicating the long-term persistence of CAR-T cells. Several studies improved the persistence through coexpression cytokines such as IL-2, IL-15, and IL-21 [2932]. Gattinoni et al. improved the therapeutic response by using sublethal dose of radiation or lymphocyte depletion [33].

Although preclinical results showed EGFRvIII-CART induces the long-term regression of metastatic lung cancer, challenges remain in clinical study. A previous clinical study reported on-target activity in the brain in patients suffering glioblastoma and infused with EGFRvIII-CART intravenously. But the in situ compensatory immunosuppressive response represented by the increased and robust expression of inhibitory molecules and infiltration of regulatory $\mathrm{T}$ cells were observed after infusion and might have blocked the effect of CAR-T cells to some extent [34]. Meanwhile, as with other treatment in solid tumor, antigen variation in lung cancer may bring obstacles in clinical practice. For these difficulties, strategies, such as combined therapy with PD-1 checkpoint blockade [35] or small molecule drugs targeting IDO-1 [36] bring promising future in CAR-T treatment in solid tumors.

Collectively, we constructed EGFRvIII-CART cells and demonstrated for the first time that EGFRvIII-CART kills lung cancer cells expressing the EGFRvIII mutation. Then, we induced the regression of metastatic lung cancer, which provided an experimental clue that EGFRvIII-CART cells can be used after surgery to clear the residual tumor cells and prevent recurrence. The therapeutic effect of EGFRvIII-CART cells should be tested in various cancer models, and the strategy of ACT especially CAR-T therapy combined with other therapies still need further study.

\section{Acknowledgements}

This study was supported by National Key Basic Research and Development Plan (No. 2015CB553701).

\section{Compliance with ethics guidelines}

Zhao Zhang, Jun Jiang, Xiaodong Wu, Mengyao Zhang, Dan Luo, Renyu Zhang, Shiyou Li, Youwen He, Huijie Bian, and Zhinan Chen declare that they have no conflict of interest. All institutional and national guidelines for the care and use of laboratory animals were followed. 
Open Access This article is distributed under the terms of the Creative Commons Attribution 4.0 International License (http:// creativecommons.org/licenses/by/4.0/), which permits unrestricted use, distribution, and reproduction in any medium, provided the appropriate credit is given to the original author(s) and the source, and a link is provided to the Creative Commons license, indicating if changes were made.

\section{References}

1. Chen W, Zheng R, Zhang S, Zhao P, Zeng H, Zou X, He J. Annual report on status of cancer in China, 2010. Chin J Cancer Res 2014; 26(1): 48-58

2. Chen W, Zheng R, Zeng H, Zhang S, He J. Annual report on status of cancer in China, 2011. Chin J Cancer Res 2015; 27(1): 2-12

3. Chen W, Zheng R, Baade PD, Zhang S, Zeng H, Bray F, Jemal A, $\mathrm{Yu}$ XQ, He J. Cancer statistics in China, 2015. CA Cancer J Clin 2016; 66(2): 115-132

4. Reck M, Rabe KF. Precision diagnosis and treatment for advanced non-small-cell lung cancer. N Engl J Med 2017; 377(9): 849-861

5. Rizvi NA, Peters S. Immunotherapy for unresectable stage III nonsmall-cell lung cancer. N Engl J Med 2017; 377(20): 1986-1988

6. Ribas A. Adaptive immune resistance: how cancer protects from immune attack. Cancer Discov 2015; 5(9): 915-919

7. Rosenberg SA, Lotze MT, Muul LM, Leitman S, Chang AE, Ettinghausen SE, Matory YL, Skibber JM, Shiloni E, Vetto JT, Seipp CA, Simpson C, Reichert CM. Observations on the systemic administration of autologous lymphokine-activated killer cells and recombinant interleukin-2 to patients with metastatic cancer. $\mathrm{N}$ Engl J Med 1985; 313(23): 1485-1492

8. Gross G, Waks T, Eshhar Z. Expression of immunoglobulin-T-cell receptor chimeric molecules as functional receptors with antibodytype specificity. Proc Natl Acad Sci USA 1989; 86(24): 1002410028

9. Maude SL, Frey N, Shaw PA, Aplenc R, Barrett DM, Bunin NJ, Chew A, Gonzalez VE, Zheng Z, Lacey SF, Mahnke YD, Melenhorst JJ, Rheingold SR, Shen A, Teachey DT, Levine BL, June CH, Porter DL, Grupp SA. Chimeric antigen receptor T cells for sustained remissions in leukemia. N Engl J Med 2014; 371(16): $1507-1517$

10. Park JH, Rivière I, Gonen M, Wang X, Sénéchal B, Curran KJ, Sauter C, Wang Y, Santomasso B, Mead E, Roshal M, Maslak P, Davila M, Brentjens RJ, Sadelain M. Long-term follow-up of CD19 CAR therapy in acute lymphoblastic leukemia. N Engl J Med 2018; 378(5): 449-459

11. Jindal V, Arora E, Gupta S. Challenges and prospects of chimeric antigen receptor T cell therapy in solid tumors. Med Oncol 2018; 35 (6): 87

12. Wikstrand CJ, Hale LP, Batra SK, Hill ML, Humphrey PA, Kurpad SN, McLendon RE, Moscatello D, Pegram CN, Reist CJ, Traweek ST, Wong AJ, Zalutsky MR and Bigner DD. Monoclonal antibodies against EGFRvIII are tumor specific and react with breast and lung carcinomas and malignant gliomas. Cancer Res 1995; 55(14): 31403148

13. Nishikawa R, Ji XD, Harmon RC, Lazar CS, Gill GN, Cavenee WK, Huang HJ. A mutant epidermal growth factor receptor common in human glioma confers enhanced tumorigenicity. Proc Natl Acad Sci USA 1994; 91(16): 7727-7731

14. Yu H, Gong X, Luo X, Han W, Hong G, Singh B, Tang CK. Coexpression of EGFRvIII with ErbB-2 enhances tumorigenesis: EGFRvIII mediated constitutively activated and sustained signaling pathways, whereas EGF-induced a transient effect on EGFRmediated signaling pathways. Cancer Biol Ther 2008; 7(11): 18181828

15. Zeineldin R, Rosenberg M, Ortega D, Buhr C, Chavez MG, Stack MS, Kusewitt DF, Hudson LG. Mesenchymal transformation in epithelial ovarian tumor cells expressing epidermal growth factor receptor variant III. Mol Carcinog 2006; 45(11): 851-860

16. Garcia de Palazzo IE, Adams GP, Sundareshan P, Wong AJ, Testa JR, Bigner DD, Weiner LM. Expression of mutated epidermal growth factor receptor by non-small cell lung carcinomas. Cancer Res 1993; 53(14): 3217-3220

17. Okamoto I, Kenyon LC, Emlet DR, Mori T, Sasaki J, Hirosako S, Ichikawa Y, Kishi H, Godwin AK, Yoshioka M, Suga M, Matsumoto M, Wong AJ. Expression of constitutively activated EGFRvIII in non-small cell lung cancer. Cancer Sci 2003; 94(1): $50-56$

18. Duan J, Wang Z, Bai H, An T, Zhuo M, Wu M, Wang Y, Yang L, Wang J. Epidermal growth factor receptor variant III mutation in Chinese patients with squamous cell cancer of the lung. Thorac Cancer 2015; 6(3): 319-326

19. Onodera M, Yachie A, Nelson DM, Welchlin H, Morgan RA, Blaese RM. A simple and reliable method for screening retroviral producer clones without selectable markers. Hum Gene Ther 1997; 8(10): 1189-1194

20. Bridgeman JS, Hawkins RE, Bagley S, Blaylock M, Holland M, Gilham DE. The optimal antigen response of chimeric antigen receptors harboring the $\mathrm{CD} 3 \zeta$ transmembrane domain is dependent upon incorporation of the receptor into the endogenous TCR/CD3 complex. J Immunol 2010; 184(12): 6938-6949

21. Heslop HE. Safer CARS. Mol Ther 2010; 18(4): 661-662

22. Carpenito C, Milone MC, Hassan R, Simonet JC, Lakhal M, Suhoski MM, Varela-Rohena A, Haines KM, Heitjan DF, Albelda SM, Carroll RG, Riley JL, Pastan I, June CH. Control of large, established tumor xenografts with genetically retargeted human $\mathrm{T}$ cells containing CD28 and CD137 domains. Proc Natl Acad Sci USA 2009; 106(9): 3360-3365

23. Alvarez-Vallina L, Hawkins RE. Antigen-specific targeting of CD28-mediated $\mathrm{T}$ cell co-stimulation using chimeric single-chain antibody variable fragment-CD28 receptors. Eur J Immunol 1996; 26(10): 2304-2309

24. Gong MC, Latouche JB, Krause A, Heston WD, Bander NH, Sadelain M. Cancer patient T cells genetically targeted to prostatespecific membrane antigen specifically lyse prostate cancer cells and release cytokines in response to prostate-specific membrane antigen. Neoplasia 1999; 1(2): 123-127

25. Morgan RA, Yang JC, Kitano M, Dudley ME, Laurencot CM, Rosenberg SA. Case report of a serious adverse event following the administration of $\mathrm{T}$ cells transduced with a chimeric antigen receptor recognizing ERBB2. Mol Ther 2010; 18(4): 843-851

26. Hatanpaa KJ, Burma S, Zhao D, Habib AA. Epidermal growth factor receptor in glioma: signal transduction, neuropathology, imaging, and radioresistance. Neoplasia 2010; 12(9): 675-684 
27. Johnson LA, Scholler J, Ohkuri T, Kosaka A, Patel PR, McGettigan SE, Nace AK, Dentchev T, Thekkat P, Loew A, Boesteanu AC, Cogdill AP, Chen T, Fraietta JA, Kloss CC, Posey AD Jr, Engels B, Singh R, Ezell T, Idamakanti N, Ramones MH, Li N, Zhou L, Plesa G, Seykora JT, Okada H, June CH, Brogdon JL, Maus MV. Rational development and characterization of humanized anti-EGFR variant III chimeric antigen receptor $\mathrm{T}$ cells for glioblastoma. Sci Transl Med 2015; 7(275): 275ra22

28. Ohno M, Ohkuri T, Kosaka A, Tanahashi K, June CH, Natsume A, Okada H. Expression of miR-17-92 enhances anti-tumor activity of T-cells transduced with the anti-EGFRvIII chimeric antigen receptor in mice bearing human GBM xenografts. J Immunother Cancer 2013; 1(1): 21

29. Hsu C, Jones SA, Cohen CJ, Zheng Z, Kerstann K, Zhou J, Robbins PF, Peng PD, Shen X, Gomes TJ, Dunbar CE, Munroe DJ, Stewart C, Cornetta K, Wangsa D, Ried T, Rosenberg SA, Morgan RA. Cytokine-independent growth and clonal expansion of a primary human $\mathrm{CD}{ }^{+} \mathrm{T}$-cell clone following retroviral transduction with the IL-15 gene. Blood 2007; 109(12): 5168-5177

30. Nagaraj S, Ziske C, Schmidt-Wolf IG. Human cytokine-induced killer cells have enhanced in vitro cytolytic activity via non-viral interleukin-2 gene transfer. Genet Vaccines Ther 2004; 2(1): 12

31. Markley JC, Sadelain M. IL-7 and IL-21 are superior to IL-2 and IL15 in promoting human $\mathrm{T}$ cell-mediated rejection of systemic lymphoma in immunodeficient mice. Blood 2010; 115(17): 3508-
3519

32. Hsu C, Hughes MS, Zheng Z, Bray RB, Rosenberg SA, Morgan RA. Primary human $\mathrm{T}$ lymphocytes engineered with a codonoptimized IL-15 gene resist cytokine withdrawal-induced apoptosis and persist long-term in the absence of exogenous cytokine. J Immunol 2005; 175(11): 7226-7234

33. Gattinoni L, Finkelstein SE, Klebanoff CA, Antony PA, Palmer DC, Spiess PJ, Hwang LN, Yu Z, Wrzesinski C, Heimann DM, Surh CD, Rosenberg SA, Restifo NP. Removal of homeostatic cytokine sinks by lymphodepletion enhances the efficacy of adoptively transferred tumor-specific CD8 ${ }^{+}$T cells. J Exp Med 2005; 202(7): 907-912

34. O'Rourke DM, Nasrallah MP, Desai A, Melenhorst JJ, Mansfield K, Morrissette JJD, Martinez-Lage M, Brem S, Maloney E, Shen A, Isaacs R, Mohan S, Plesa G, Lacey SF, Navenot JM, Zheng Z, Levine BL, Okada H, June CH, Brogdon JL, Maus MV. A single dose of peripherally infused EGFRvIII-directed CAR T cells mediates antigen loss and induces adaptive resistance in patients with recurrent glioblastoma. Sci Transl Med 2017; 9(399): eaaa0984

35. Chen N, Morello A, Tano Z, Adusumilli PS. CAR T-cell intrinsic PD-1 checkpoint blockade: a two-in-one approach for solid tumor immunotherapy. OncoImmunology 2017; 6(2): e1273302

36. Huang Q, Xia J, Wang L, Wang X, Ma X, Deng Q, Lu Y, Kumar M, Zhou Z, Li L, Zeng Z, Young KH, Yi Q, Zhang M, Li Y. miR-153 suppresses IDO1 expression and enhances CAR T cell immunotherapy. J Hematol Oncol 2018; 11(1): 58 